\title{
Chemical compositions, antioxidant and antimicrobial activities of Tubu (Pycnarrhena longifolia) leaves used as ingredient in traditional functional foods
}

\author{
${ }^{3}$ Mohammed, N.K., ${ }^{1}$ Muhialdin, B.J., ${ }^{1}$ Masri, N.S., ${ }^{1}$ Sukor R., ${ }^{4}$ Abd-El Aziem, F. and \\ $1,2^{*}$ Meor Hussin A.S. \\ ${ }^{I}$ Faculty of Food Science and Technology, Universiti Putra Malaysia, 43400 UPM Serdang, Selangor, \\ Malaysia \\ ${ }^{2}$ Halal Products Research Institute, Universiti Putra Malaysia, 43400 UPM Serdang, Selangor, Malaysia \\ ${ }^{3}$ Food Science Department, Faculty of Agriculture, Tikrit University, 43001 Tikrit, Iraq \\ ${ }^{4}$ Molecular Biotechnology and Utilization of Resources Research Group, Department of Biotechnology, \\ Faculty of Science, Taif University, Al-Hawiya 888, Saudi Arabia
}

\begin{abstract}
Article history:
Received: 12 August 2019

Received in revised form: 19

December 2019

Accepted: 29 December 2019

Available Online: 21 January 2020
\end{abstract}

Keywords:

Pycnarrhena longifolia,

Biological activity,

Minerals,

Bioactive compounds,

Amino acid

DOI:

https://doi.org/10.26656/fr.2017.4(3).285

\begin{abstract}
Tubu (Pycnarrhena longifolia) leaves are known as food enhancer and medicinal plant by several ethnics of Malaysia. The aims of the study were to determine the tubu leaves composition and biological activity including antioxidant and antibacterial. The mineral, sugar and amino acids were determined using HPLC, and bioactive compounds using GCMS. The antioxidant activity was evaluated by DPPH assay, and the antibacterial activity screened by disc diffusion method. The dry leaf compositions were $6.6 \%$ moisture, $11.6 \%$ ash, $7.0 \%$ crude protein, $15.7 \%$ crude fiber, $12.1 \%$ crude fat and carbohydrate $47 \%$. A total of seven minerals were present in the methanol extract and the highest content was for iron $(159.5 \mathrm{mg})$ and calcium $(16.8 \mathrm{mg})$. The sugar profile showed high sugar content for glucose, sucrose, rhamnose, and fructose which was $8,13,7$, and $20 \mathrm{mg} / \mathrm{g}$, respectively. A total of sixteen amino acids was present in the tubu leaf extract, and seven bioactive compounds were identified by GC-MS/MS. The antioxidant activity was $87 \%$, total phenolic compound content was $26.49 \mathrm{mg} / \mathrm{mL}$ and total flavonoid content was 13.39 $\mathrm{mg} / \mathrm{mL}$. Tubu leaves showed antibacterial activity towards Salmonella enterica serovar Typhimurium, Escherichia coli, Bacillus cereus and Staphylococcus aureus. This study showed that tubu leaves had rich sources of amino acids, minerals, sugars and bioactive compounds, potential to be a functional food ingredient.
\end{abstract}

\section{Introduction}

Tubu (Pycnarrhena longifolia) leaves is a medicinal plant that is used as natural food enhancer in cooking by Iban, Kenyah, Kayan, Bidayuh, and Kelabit ethnics in East Malaysia. There are many claims of it is health benefits such as reducing fever and prevent skin diseases (Kulip et al., 2003). Tubu leaves are locally known as "daun sengkubak" or "appak", and their scientific name is Pycnarrhena Longifolia. There are six species belongs to this plant including Pycnarrhena longifolia, Pycnarrhena cauliflora, Pycnarrhena celebica, Pycnarrhena lucida. Pycnarrhena novoguineensis and Pycnarrhena tumefacta (Bold Systems, 2014). The plant usually found in hilly areas, above 500-1500 meters from the sea level and it is slender twining shrub and frequently climbing up on tall trees. The traditional method to prepare the plant extract is by boiling the leaves in hot water for $30 \mathrm{mins}$, and the extract consumed to reduce headache and fever. Tubu leaves has unique flavor that is known as Umami taste, is the term used for savory-like taste sensation, which in Japanese means "delicious flavor". The increased health concerns among consumers worldwide have increased the demand for bioactive ingredients and functional foods. In addition, natural food enhancer can be used to overcome the problem of using chemically synthetic flavors for food applications. The umami taste may be very useful for certain groups of consumers such as elderly as the smell and taste sensitivity is reduced by aging. Consumption of phenolic and flavonoid-rich foods can bring a lot of health benefits to humans (Biglari et al., 2008). Plant-derived foods especially the raw and unprocessed fruits and vegetables are often associated with high content of antioxidants and antimicrobial compounds. Several studies exhibited that consumption 
of fruits and vegetables can lower the occurrence of heart disease, cancer, gastrointestinal and liver diseases (Shankar et al., 2007; Kampa et al., 2007). There are several medicinal plants with valuable health benefits and have high potential for food applications but is not well studied such as tubu leaves. Therefore, this study aims to determine the content of mineral, sugar, amino acids, and bioactive compounds tubu leaves. Moreover, the antioxidant activity and antibacterial activity of the leaves extract will be evaluated.

\section{Materials and methods}

\subsection{Samples preparation}

Tubu leaves were obtained from the Universiti Putra Malaysia (UPM) from 5 years old trees. The leaves were collected from 3 different trees to observe any significant variations in content and activity. The sample selected was free from defects and mechanical damage. The leaves were immediately frozen at $-18^{\circ} \mathrm{C}$ in the freezer for $24 \mathrm{hrs}$. The fine powder was obtained by grounding the leaves, which was passed through sieve number 212 $\mathrm{mm}$ to obtain a homogenous sample size and the powder was subjected to freeze dry (Scanvac Coolsafe, Scandinavia). Furthermore, $10 \mathrm{~g}$ of sample was soaked in $100 \mathrm{~mL}$ of $80 \%$ methanol in conical flask for two days and sample was extracted using rotary evaporator at $60^{\circ}$ $\mathrm{C}$ and $90 \mathrm{rpm}$.

\subsection{Proximate analysis}

The proximate analysis of the samples for moisture, ash, crude protein, crude fiber, fat and carbohydrate according to the procedures described by AOAC International (2005). All the analyses were performed in triplicate.

\subsection{Sugar and mineral analysis}

The sugar content of tubu leaves was determined following the method described by Shanmugavelan et al. (2013). The extract was prepared by dissolving $0.15 \mathrm{~g}$ of powder sample in $20 \mathrm{~mL}$ ethanol by well stirring for 20 mins at room temperature using a magnetic stirrer followed by sonication for 10 mins and further stirring for 5 mins. Then, the mixture was centrifuged at $4^{\circ} \mathrm{C}$ in $3000 \mathrm{rpm}$ for $10 \mathrm{mins}$. The supernatant solution was filtered through a $0.2 \mu \mathrm{m}$ membrane filter and transferred into $1.5 \mathrm{~mL}$ vials. The sugar content was determined using High Pressure Liquid Chromatography (HPLC) (Waters 600 liquid chromatograph) connected with the detector (Model 410). The mobile phase was mixture of acetonitrile: water (80:20). For quantification and calibration, a standard solution mixture was prepared by dissolving glucose, sucrose, fructose, xylose and rhamnose in acetonitrile: water (50:50) mixture for four different concentration levels (5000, 10000, 15000, $20000 \mathrm{ppm}$ ). Mineral analyses were determined using air -acetylene flame Atomic Absorption Spectrophotometer (Perkin Elmer, Japan). Seven elements of minerals that are sodium, potassium, calcium, magnesium, iron, copper and zinc were determined. The accuracy of the result was verified by the formula below.

\section{Formula of F-AAS $=[$ RPM X 100/1000mL $] /$ Mass}

\subsection{Amino acid analysis using HPLC}

Amino acid content was carried out to determine the nutritional value of the tubu leaves. Amino acid analysis was determined following the method from Wang et al. (2010) with slight modification. The dried sample $(0.57$ g) was dissolved in $15 \mathrm{~mL}$ of $6 \mathrm{~N} \mathrm{HCI}$ and stored in the oven for $24 \mathrm{hrs}$. After that, $10 \mathrm{~mL}$ of AABA (internal standard) was added for each sample and the volumetric flask $(50 \mathrm{~mL})$ was made up with deionized water. The samples were filtered before the injection of $20 \mu \mathrm{L}$ of the sample for the analysis using HPLC (Waters 600 liquid chromatograph).

\subsection{GC/MS analysis}

The GC/MS analysis was carried out following the method of Kim and Shin et al. (2005) with some modification. Tubu leaves were extracted by using methanol $100 \%$ and the extract samples were injected into a CG-MS system (TSQ $^{\mathrm{TM}} 8000$ Evo Triple Quadrupole GC-MS/MS, Massachusetts, USA) using chromatography column: Thermo TR-5, $(60.0 \mathrm{~m} \times 0.25$ $\mathrm{mm} \times 0.25 \mu \mathrm{m})$. Helium was used as the carrier gas at a flow rate of $1 \mathrm{~mL} / \mathrm{min}$. the temperature set at $60^{\circ} \mathrm{C}$ and then increased to $220^{\circ} \mathrm{C}$ (maintain for $1 \mathrm{~min}$ ). The mass spectrum library (Wiley NBS 139) was used to determine the components of the extract by comparing the spectra obtained from the samples with the GC library against known standards. Each determination was carried out in triplicate and the identification of the compounds was confirmed by matching the peak spectra in Human Metabolome Database (HMDB).

\subsection{Antioxidant activity}

The antioxidant activity of tubu leaves was determined by using radical scavenging activity (DPPH) assay as described by Abdel-Hameed et al. (2012). One gram of the sample was dissolved in $50 \mathrm{~mL}$ of methanol at room temperature for $1 \mathrm{hr}$. The extract was filtered through the paper filter using vacuum filtration. The flavonoid and total phenolic contents of the sample were determined following the method described by AbdelHameed et al. (2012). The total phenolic contents of the samples were determined using Folin-Ciocalteu's reagent (FCR). The flavonoids content was determined 
by the aluminum chloride method using rutin as a reference compound.

\subsection{Antibacterial activity}

The antibacterial activity test was carried out by using disc diffusion method against four namely Salmonella enterica serovar Typhimurium, Escherichia coli, Bacillus cereus and Staphylococcus aureus. The pathogen suspension was prepared by growing the bacteria in nutrient broth at $37^{\circ} \mathrm{C}$ for $24 \mathrm{hrs}$. The optical density was measured at wavelength $600 \mathrm{~nm}$ and the viable cells were determined using nutrient agar. The pathogen suspension was adjusted to approximately $10^{6}$ $\mathrm{CFU} / \mathrm{mL}$ and seeded on nutrient agar plates by cotton swap. The tubu extract $(15 \mu \mathrm{L})$ was dispensed on the 6 $\mathrm{mm}$ filter discs placed in nutrient agar plates. The agar plates were then incubated at $37^{\circ} \mathrm{C}$ for $24 \mathrm{hrs}$. The diameter of the zones of complete inhibition was measured including the diameter of the positive control disc which is chloramphenicol $30 \mu \mathrm{g}$ and negative control which is $100 \%$ methanol.

\subsection{Statistical analysis}

All experiments were carried out in triplicate and the obtained data was analysed by one-way analysis of variance (ANOVA) using MINITAB16. The mean values difference was set at $\mathrm{p}<0.05$ which is considered significant.

\section{Results and discussion}

\subsection{Proximate analysis}

Table 1. Proximate analysis of tubu leaves

\begin{tabular}{cc}
\hline Components & Content \\
\hline Moisture & $6.60 \%$ \\
Ash & $11.60 \%$ \\
Crude protein & $7.00 \%$ \\
Crude fiber & $15.70 \%$ \\
Crude fat & $12.10 \%$ \\
Carbohydrate & $47.60 \%$ \\
\hline
\end{tabular}

The proximate analysis was carried out to determine the constituent for the tubu leaves. The results showed high carbohydrate content in tubu leaves (Table 1). Moreover, these results confirmed that tubu leaves is a good source of protein as determined in this study. The other chemical compositions of dry tubu leaves were $6.6 \%$ moisture, $11.6 \%$ ash, $15.7 \%$ fiber and $12.1 \%$ crude fat. There are very limited data about tubu leaves and there are no previous proximate analysis results that can be used for comparison with the finding of this study. However, several approximate analyses for plant leaves demonstrated similar results for the chemical composition except for the fat content. In this study, the fat content was observed to be very high for plant leaves as reported in previous studies (Oluwatoyin et al., 2012; Shukla et al., 2015).

\subsection{Sugar and mineral analysis}

The sugar profile for tubu leaves is very important because they serve as a primary fuel for energy production of the body and for the biological functions. Several plant extracts are a rich source of sugars that can be used as food ingredients to improve the taste of the food products. The results showed four types of sugar were present in the leave extract namely glucose, sucrose, fructose and rhamnose at concentrations of 7.87, 12.83, 20 and 7.40, respectively (Table 2). The sugars present in the tubu leave extract are among the most important carbohydrates that provide energy for the body and they are important for the food industry as they have been used as alternative sweeteners (Levin et al., 1995). Goyal and Goyal (2010) studied the extract of stevia and the application in the food industry and the results showed that stevia extract is a suitable alternative biosweetener for bulk sugars. The benefits of using plant extract as bio-sweeteners involve the high content of other compounds that will improve the nutritional value of the food products. On the other hand, carbohydrates and sugars are used as an energy source for the growth and development of plants. The high content of sugars of tubu leaf is favorable for the food industry, and the dried leaves powder can be added to several foods to improve the taste and a source of natural energy.

Table 2. Sugar and minerals content of the dry tubu leaves

\begin{tabular}{cccc}
\hline \multicolumn{2}{c}{ Minerals content $\mathrm{mg} / \mathrm{g}$} & \multicolumn{2}{c}{ Sugars content $\mathrm{mg} / \mathrm{g}$} \\
\hline $\mathrm{Ca}$ & $16.8 \pm 0.22$ & Glucose & $7.87 \pm 0.09$ \\
$\mathrm{~K}$ & $6.6 \pm 0.14$ & Sucrose & $12.83 \pm 0.42$ \\
$\mathrm{Zn}$ & $0.6 \pm 0.43$ & Fructose & $20.06 \pm 0.51$ \\
$\mathrm{Na}$ & $1.4 \pm 0.07$ & Rhamnose & $7.40 \pm 1.70$ \\
$\mathrm{Mg}$ & $1.2 \pm 0.67$ & & \\
$\mathrm{Fe}$ & $159.5 \pm 0.79$ & & \\
$\mathrm{Cu}$ & $3.5 \pm 0.24$ & & \\
\hline
\end{tabular}

Results are expressed as mean of three values \pm standard deviation

The mineral content results showed the mineral mixture present in tubu leaves at different concentrations which include $16.8 \mathrm{mg} / \mathrm{g}, 6.6 \mathrm{mg} / \mathrm{g}, 0.6 \mathrm{mg} / \mathrm{g}, 1.4 \mathrm{mg} / \mathrm{g}$, $1.2 \% \mathrm{mg} / \mathrm{g}, 159.5 \mathrm{mg} / \mathrm{g}$ and $3.5 \mathrm{mg} / \mathrm{g}$ for $\mathrm{Ca}, \mathrm{K}, \mathrm{Zn}, \mathrm{Na}$, $\mathrm{Mg}, \mathrm{Fe}$ and $\mathrm{Cu}$ respectively. However, the highest mineral concentration was for Fe which is very important for the hemoglobin and myoglobin production in the body and enzymes activity including peroxidase, catalase, hydroxylase and flavin enzymes. In addition, tubu leaves are a very good source for the minerals $\mathrm{Ca}$, $\mathrm{Na}$ and $\mathrm{K}$ that are important for the human diet and the 
daily recommended intake is $>50 \mathrm{mg} /$ day. The consumption of minerals is essential for the human body to maintain the normal growth rate and to support the immune system from infections (Barringer et al., 2003). In the previous study, researchers observed the enhancement of bone density due to the high intake of yogurt that contains several minerals and it was a very good source for minerals (Laird et al., 2017). However, excessive intake of certain minerals such as sodium may cause hypertension and it should be avoided (Hounsome et al., 2008; Belitz et al., 2009). Plants are a promising source of essential minerals and trace elements that fulfil the nutritional needs to overcome the losses of nutritional compounds due to modern diets such as fast foods, generally favorite foods for kids.

\subsection{Amino acid analysis}

Table 3. Amino acid content of the dry tubu leaves determined by HPLC

\begin{tabular}{cc}
\hline Phenolic compound & Content $(\mathrm{mg} / \mathrm{g})$ \\
\hline Aspartic Acid (Asp) & $36.60 \pm 0.09$ \\
Glutamic Acid (Glu) & $37.66 \pm 0.09$ \\
Serine (Ser) & $13.64 \pm 0.09$ \\
Glycine (Gly) & 15.61 \\
Histidine (His) & 6.05 \\
Arginine (Arg) & 2.14 \\
Threonine+Alanine (Thr+Ala) & 22.64 \\
Proline (Pro) & 15.16 \\
Tyrosine (Try) & 9.57 \\
Valine (Val) & 15.92 \\
Methionine (Met) & 4.58 \\
Cystine (Cys) & 1.32 \\
Isoleucine (Ile) & 24.46 \\
Leucine (Leu) & 22.83 \\
Phenylalanine (Phe) & 16.21 \\
Lysine (Lys) & 7.31 \\
\hline
\end{tabular}

Results are expressed as mean of three values \pm standard deviation

The amino acid profile of tubu leaves extraction demonstrated the presence of 17 amino acids that were detected from HPLC analysis including glutamic acid, serine, glycine, histidine, arginine, threonine, alanine, proline, tyrosine, valine, methionine, cystine, isoleucine, leucine, phenylalanine and lysine (Table 3). Aspartic acid and glutamic acid were the highest amino acid occurred in tubu leaves at concentrations of $36.60 \mathrm{mg} / \mathrm{g}$ and $37.66 \mathrm{mg} / \mathrm{g}$ respectively. Additionally, cysteine was very low $(1.32 \mathrm{mg} / \mathrm{g})$ compared to other amino acids. Glutamate is one of the important amino acids that can provide savoury flavor and enhance the taste of food that was especially existed in current food product and food enhancer (Oruna-Concha et al., 2007; Jinap and Hajeb, 2010). The results in this study showed the presence of essential amino acids in tubu leaves that have several functions in human body such as, immune function, hormones production, enzymes activity, and antibodies activity. The dried tubu leaves demonstrated promising potential as a functional ingredient for functional foods.

\subsection{GC/MS analysis}

Seven bioactive compounds were identified by the GC-MS/MS analysis and these compounds have high biological activity in the human body. The compounds were detected at retintion time between 10-25 mins and highly matched with the MS data (Figure 1). The compounds found in tubu leaves had low molecular weights ranged between 204-390 Da (Table 4). The identified compounds had very well known biological activities, for example, á-Bourbonene which has antiinflammatory activity and broad-spectrum antimicrobial activity (Yu et al., 2004). In addition, spathulenol was identified in the tubu extract and this compound was previously reported to play a very important role to improve the human immune system response to infections (Verdeguer et al., 2009). The compound áylangene is food flavouring which has earthy and spicy tastes (Parker et al., 2007). Phenolic compounds are an important part of the human diet and they play an important role to improve the health of the consumers. Moreover, studies demonstrated that phenolic compounds have many biological activities including anticancer, anti-hypertension, anti-diabetic, antiinflammatory and antimicrobial (Cai et al., 2004). The results indicate that tubu leaves are not only important food flavour enhancer but also a valuable source of phenolic compounds that have several biological activities.

Table 4. Chemical compositions of tubu leaves identified by GC/MS

\begin{tabular}{ccccc}
\hline No. & & M.W & RT & Composition \% \\
\hline 1 & á-Bourbonene & 204 & 10.32 & 0.5 \\
2 & á-ylangene & 204 & 11.15 & 0.46 \\
3 & á-copaene & 204 & 11.61 & 1.33 \\
4 & Spathulenol & 220 & 12.98 & 0.76 \\
5 & Diethyl Phthalate & 222 & 13.3 & 3.38 \\
6 & Carbonic acid & 390 & 15.37 & 3.85 \\
7 & 17-Octadecynoic acid & 280 & 18.85 & 44.57 \\
\hline
\end{tabular}

M.W: molecular weight, RT: retention time

\subsection{Antioxidant activity}

The results demonstrated very high antioxidant activity of tubu leaves extract (87\%) indicated by DPPH assay. Plant extracts have antioxidant activity due to the high phenolic compound contents that have scavenging activity for free radicals and can reduce the oxidation stress in the body (Mohammed et al., 2016). AL-Zuaidy et al. (2016) reported high antioxidant activity evaluated by DPPH for the ethanolic extract of Melicope lunu- 


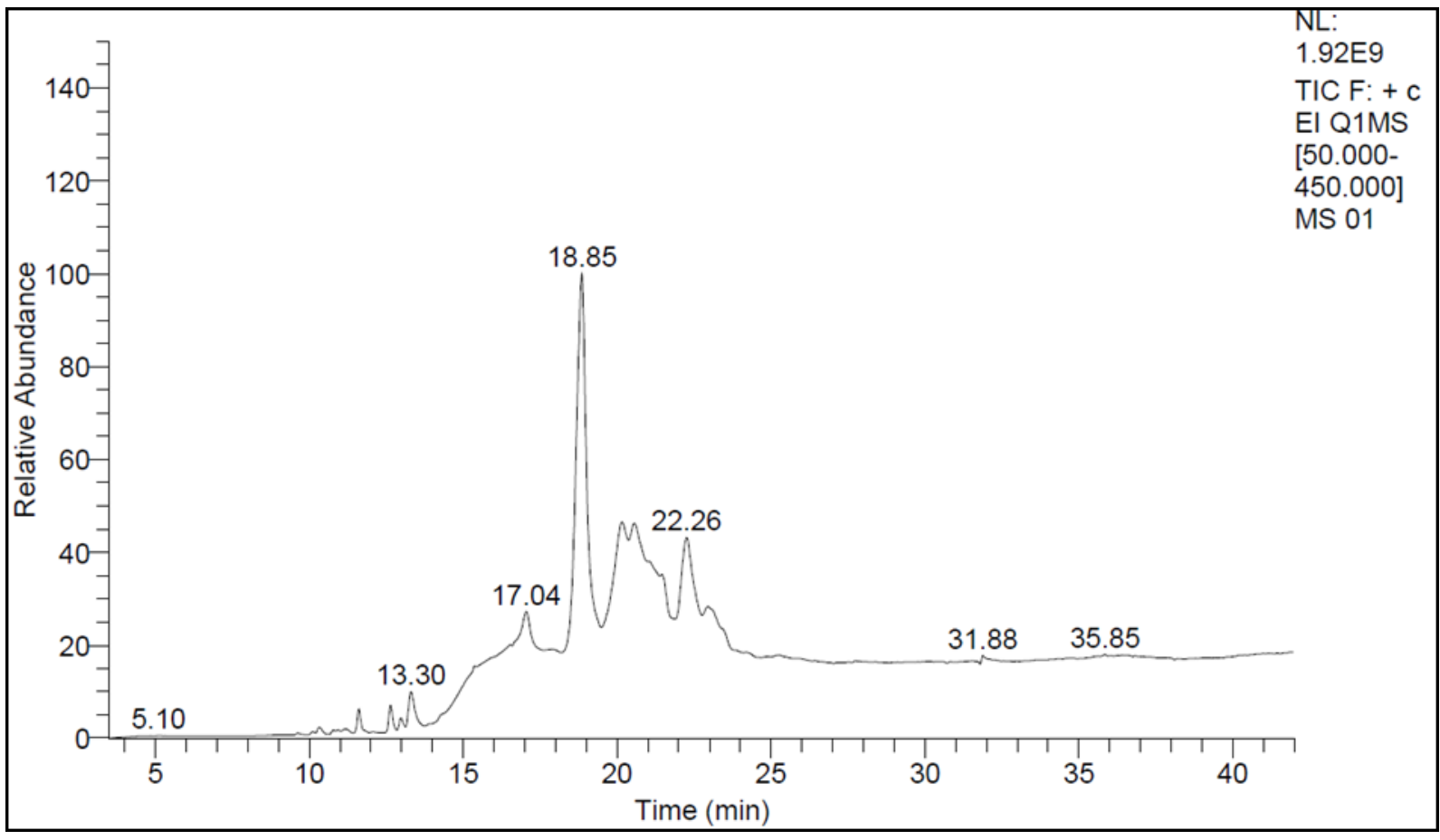

Figure 1. GC/MS chromatography analysis of tubu leaves extract

ankenda leaves which showed high inhibitory effect. This study finding was in compliance with results of Othman et al. (2014) as he studied four different local Malaysian plants namely Melicope lunuankenda, Polygonum minus, Murraya koenigii and Eugenia polyantha extracted with methanol demonstrated high antioxidant activity and phenolic compounds measured by DPPH assay and TPC. On the other hand, the total phenolic content of the tubu extract revealed a high content of total phenolic and total flavonoid compounds $26.49 \mathrm{mg} / \mathrm{g}$ and $13.39 \mathrm{mg} / \mathrm{g}$, respectively (Table 5). Tubu leaves showed high value for the total phenolic compound (TPC) in compared to other herbs conducted from the same region. Wojdyło et al. (2007) reported that the TPC value for tubu leaves was high in comparison with other 15 leafy herbs from the same region. On the other hand, total flavonoid compound was $13.93 \mathrm{mg} / \mathrm{mL}$ which is also high value compared to other leafy vegetable samples in tropical countries. Researchers suggested that a great number of diseases can be prevented by high intakes of flavonoids (Kähkönen et al., 1999).

Table 5. Antioxidant activity, total phenolic compounds and total flavonoid compounds of tubu leaves

\begin{tabular}{cc}
\hline Antioxidant & Content \\
\hline DPPH & $87.27 \pm 0.25 \%$ \\
Total phenolic compound (TPC) & $26.49 \pm 2.78 \mathrm{mg} / \mathrm{mL}$ \\
Total flavonoid compound (TFC) & $13.39 \pm 3.31 \mathrm{mg} / \mathrm{mL}$ \\
\hline
\end{tabular}

Results are expressed as mean of three values \pm standard deviation

\subsection{Antibacterial activity}

The antibacterial activity of tubu leaves was determined by disc diffusion method and is measured by the clear zone around the discs in $\mathrm{mm}$. The methanolic extract obtained from tubu leaves was tested using the disc diffusion assay at different concentrations including $80,60,40$, and $20 \mathrm{mg} / \mathrm{mL}$ against two Gram-positive (E. coli and $S$. enterica serovar Typhimurium) and two Gram-negative (B. cereus and $S$. aureus) pathogenic bacteria. The results demonstrated the effects of tubu extract on four selected pathogens and the correlation between antibacterial activity and the extract concentration (Table 6). The antibacterial activity of tubu leaves was moderated and slightly increased with higher concentrations. The extract inhibited the growth of the four selected pathogens and the most sensitive pathogen was $S$. aureus. However, the positive control showed strong antibacterial activity and the diameter ranged between 14 and $24 \mathrm{~mm}$, while the negative control did not show any antibacterial activity. The antibacterial activity of plant extracts is suggested to be due to the presence of high content of phenolic compounds (Bhalodia and Shukla, 2011). In this study, tubu leaves extract demonstrated the correlation between the high content of phenolic compounds and flavonoids, and the antibacterial activity. The results study showed the potential applications of the dried tubu leaves and their extract as ingredients bio-preservative agent in functional foods.

\section{Conclusion}

Tubu leaves were found to be a rich source of minerals, sugars, amino acids, and bioactive compounds. The content of amino acid and the bioactive compounds is higher than other plants in the same region. The high sugar content included glucose, sucrose, rhamnose, and 
Table 6. Antibacterial activities of the tubu leaves extracts against selected pathogens after $24 \mathrm{hrs}$ incubation at $37^{\circ} \mathrm{C}$

\begin{tabular}{|c|c|c|c|c|}
\hline & Escherichia coli & Bacillus cereus & $\begin{array}{c}\text { Salmonella enterica } \text { serovar } \\
\text { Typhimurium }\end{array}$ & Staphylococcus aureus \\
\hline $80 \%$ extract & $7.67 \pm 0.58^{\mathrm{ab}}$ & $8.67 \pm 0.58^{b}$ & $7.00 \pm 0.00^{b}$ & $9.33 \pm 0.58^{b}$ \\
\hline $60 \%$ extract & $7.67 \pm 0.58^{\mathrm{ab}}$ & $8.00 \pm 0.00^{b}$ & $7.00 \pm 0.00^{\mathrm{b}}$ & $8.67 \pm 0.58^{b c}$ \\
\hline $40 \%$ extract & $7.00 \pm 0.00^{\mathrm{b}}$ & $7.67 \pm 0.58^{b}$ & $7.00 \pm 0.00^{\mathrm{b}}$ & $7.67 \pm 0.58^{b c}$ \\
\hline $20 \%$ extract & $7.33 \pm 0.58^{b}$ & $7.33 \pm 0.58^{b}$ & $6.33 \pm 0.58^{b}$ & $7.33 \pm 0.58^{\mathrm{bc}}$ \\
\hline Negative control & $6.00 \pm 0.00^{\mathrm{a}}$ & $6.00 \pm 0.00^{\mathrm{a}}$ & $6.00 \pm 0.00^{\mathrm{a}}$ & $6.00 \pm 0.00^{\mathrm{a}}$ \\
\hline $\begin{array}{l}\text { Positive control } \\
\text { Chloramphenicol } 30 \mu \mathrm{g}\end{array}$ & $14.00 \pm 6.08^{\mathrm{a}}$ & $42.67 \pm 1.53^{\mathrm{a}}$ & $19.00 \pm 3.61^{\mathrm{a}}$ & $22.67 \pm 2.52^{\mathrm{a}}$ \\
\hline
\end{tabular}

Results are expressed as mean of three values \pm standard deviation. The same superscripts in the same column denote no significant different $(\mathrm{p}>0.05)$.

fructose found in tubu leaves can improve the flavor when added to selected foods. In addition, phenolic and flavonoid content of tubu leaves were in a considerable amount that can be used as a natural antioxidant source. Moreover, the antibacterial activity of tubu leaves can enhance the functional properties of foods. Tubu leaves can be commercialized as a new natural food flavor enhancers and bioactive ingredients for functional foods. Further study should be carried to determine the cytotoxicity of the powder and optimize the quantity to be added to foods for optimum function. Moreover, the effect of food process on the bioactive compounds and their biological activity should be considered for future studies.

\section{Conflict of Interest}

The authors declare no conflict of interest.

\section{Acknowledgment}

This work was supported by the FRGS grant from Malaysian Ministry of Higher Education with the grant number 02-02-13-1353FR.

\section{References}

Abdel-Hameed, E.S.S., Bazaid, S.A. and Shohayeb, M.M. (2012). Total phenolics and antioxidant activity of defatted fresh Taif rose, Saudi Arabia. British Journal of Pharmaceutical Research, 2(3), 129-140. https://doi.org/10.9734/BJPR/2012/1493

AL-Zuaidy, M.H., Hamid, A.A., Ismail, A., Mohamed, S., Abdul Razis, A.F., Mumtaz, M.W. and Salleh, S.Z. (2016). Potent Antidiabetic Activity and Metabolite Profiling of Melicope lunu-ankenda Leaves. Journal of Food Science, 81(5), C1080C1090. https://doi.org/10.1111/1750-3841.13293

AOAC International. (2005). Official methods of analysis of AOAC International. Arlington, USA: AOAC International.

Barringer, T.A., Kirk, J.K., Santaniello, A.C., Foley,
K.L. and Michielutte, R. (2003). Effect of a Multivitamin and Mineral Supplement on Infection and Quality of Life: A Randomized, Double-Blind, Placebo-Controlled Trial. Annals of Internal Medicine. 138(5), 365-371. https:// doi.org/10.7326/0003-4819-138-5-200303040-00005

Belitz, H.D., Grosch, W. and Schieberle, P. (Eds.) (2009). Food Chemistry, 4th ed., p. 62-63. Heidelberg, Germany: Springer.

Bhalodia, N.R. and Shukla, V.J. (2011). Antibacterial and antifungal activities from leaf extracts of Cassia fistula L.: An ethnomedicinal plant. Journal of Advanced Pharmaceutical Technology and Research, 2(2), 104-109. https:// doi.org/10.4103/2231-4040.82956

Biglari, F., AlKarkhi, A.F. and Easa, A.M. (2008). Antioxidant activity and phenolic content of various date palm (Phoenix dactylifera) fruits from Iran. Food Chemistry, 107(4), 1636-1641. https:// doi.org/10.1016/j.foodchem.2007.10.033

Bold Systems. (2014). Pycnarrhena longifolia \{species\}Magnoliophyta; Magnoliopsida; Ranunculales; Menispermaceae; Pycnarrhena. Retrieved $17^{\text {th }}$ May 2016 from http://www.boldsystems.org/index.php/ Taxbrowser_Taxonpage?taxid $=554278$

Cai, Y., Luo, Q., Sun, M. and Corke, H. (2004). Antioxidant activity and phenolic compounds of 112 traditional Chinese medicinal plants associated with anticancer. Life Sciences, 74, 2157-2184. https:// doi.org/10.1016/j.1fs.2003.09.047

Goyal, S.K. and Goyal, R.K. (2010). Stevia (Stevia rebaudiana) a bio-sweetener: a review. International journal of food sciences and nutrition, 61(1), 1-10. https://doi.org/10.3109/09637480903193049

Hounsome, N., Hounsome, B., Tomos, D. and EdwardsJones, G. (2008). Plant metabolites and nutritional quality of vegetables. Journal of Food Science, 73 (4), R48-R65. https://doi.org/10.1111/j.17503841.2008.00716.x

Jinap, S. and Hajeb, P. (2010). Glutamate. Its 
applications in food and contribution to health. Appetite, 55(1), 1-10. https://doi.org/10.1016/ j.appet.2010.05.002

Kähkönen, M.P., Hopia, A.I., Vuorela, H.J., Rauha, J.P., Pihlaja, K., Kujala, T.S. and Heinonen, M. (1999). Antioxidant activity of plant extracts containing phenolic compounds. Journal of Agricultural and Food Chemistry, 47(10), 3954-3962. https:// doi.org/10.1021/jf9901461

Kampa, M., Nifli, A.P., Notas, G. and Castanas, E. (2007). Polyphenols and cancer cell growth. In Amara, S.G., Bamberg, E., Fleischmann, B., Gudermann, T., Hebert, S.C., Jahn, R., Lederer, W.J., Lill, R., Miyajima, A., Offermanns, S. and Zechner, R. (Eds.). Reviews of physiology, biochemistry and pharmacology, p. 79-113. Berlin, Germany: Springer. https:// doi.org/10.1007/112_2006_0702

Kim, Y.S. and Shin, D.H. (2005). Volatile components and antibacterial effects of pine needle (Pinus densiflora S. and Z.) extracts. Food Microbiology, 22(1), 37-45. https://doi.org/10.1016/ j.fm.2004.05.002

Kulip, J. (2003). An ethnobotanical survey of medicinal and other useful plants of Muruts in Sabah, Malaysia. Telopea, 10(1), 81-98. https:// doi.org/10.7751/telopea20035608

Laird, E. Molloy, A.M., McNulty, H., Ward, M., McCarroll, K., Hoey, L., Hughes, C.F., Cunningham, C., Strain, J.J.M. and Casey, C. (2017). Greater yogurt consumption is associated with increased bone mineral density and physical function in older adults. Osteoporos International, 28, 2409-2419. https://doi.org/10.1007/s00198-017-4049-5

Levin, G.V., Zehner, L.R., Saunders, J.P. and Beadle, J.R. (1995). Sugar substitutes: their energy values, bulk characteristics, and potential health benefits. The American Journal of Clinical Nutrition, 62(5), 1161S-1168S. https:// doi.org/10.1093/ajen/62.5.1161S

Mohammed, N.K., Abd Manap, M.Y., Tan, C.P., Muhialdin, B.J., Alhelli, A.M. and Meor Hussin A.S. (2016). The Effects of Different Extraction Methods on Antioxidant Properties, Chemical Composition, and Thermal Behavior of Black Seed (Nigella sativa L.) Oil. Evidence-Based Complementary and Alternative Medicine, 2016, 6273817. https:// doi.org/10.1155/2016/6273817

Oruna-Concha, M. J., Methven, L., Blumenthal, H., Young, C. and Mottram, D.S. (2007). Differences in glutamic acid and 5'-ribonucleotide contents between flesh and pulp of tomatoes and the relationship with umami taste. Journal of Agricultural and Food
Chemistry, 55, 5776-5780. https://doi.org/10.1021/ jf070791p

Othman, A., Mukhtar, N.J., Ismail, N.S. and Chang, S.K. (2014). Phenolics, flavonoids content and antioxidant activities of 4 Malaysian herbal plants. International Food Research Journal, 21(2), 759-766.

Parker, M., Pollnitz, A.P., Cozzolino, D., Francis, I.L. and Herderich, M.J. (2007). Identification and quantification of a marker compound for 'pepper' aroma and flavor in shiraz grape berries by combination of chemometrics and gas chromatography-mass spectrometry. Journal of Agricultural and Food Chemistry, 55(15), 59485955. https://doi.org/10.1021/jf0705320

Shankar, S., Ganapathy, S. and Srivastava, R.K. (2007). Green tea polyphenols: biology and therapeutic implications in cancer. Frontiers in Bioscience, 12, 4881-4899. https://doi.org/10.2741/2435

Shanmugavelan, P., Kim, S.Y., Kim, J.B., Kim, H.W., Cho, S.M., Kim, S.N., Kim, S.Y., Cho, Y.S. and Kim, H.R. (2013). Evaluation of sugar content and composition in commonly consumed Korean vegetables, fruits, cereals, seed plants, and leaves by HPLC-ELSD. Carbohydrate Research, 380, 112117. https://doi.org/10.1016/j.carres.2013.06.024

Verdeguer, M., Blázquez, M.A. and Boira, H. (2009). Phytotoxic effects of Lantana camara, Eucalyptus camaldulensis and Eriocephalus africanus essential oils in weeds of Mediterranean summer crops. Biochemical Systematics and Ecology, 37(4), 362369. https://doi.org/10.1016/j.bse.2009.06.003

Wang, L., Xu, R., Hu, B., Li, W., Sun, Y., Tu, Y. and Zeng, X. (2010). Analysis of free amino acids in Chinese teas and flower of tea plant by high performance liquid chromatography combined with solid-phase extraction. Food Chemistry, 123(4), 1259-1266.

https://doi.org/10.1016/ j.foodchem.2010.05.063

Wojdyło, A., Oszmiański, J. and Czemerys, R. (2007). Antioxidant activity and phenolic compounds in 32 selected herbs. Food Chemistry, 105(3), 940-949. https://doi.org/10.1016/j.foodchem.2007.04.038

Yu, J., Lei, J., Yu, H., Cai, X. and Zou, G. (2004). Chemical composition and antimicrobial activity of the essential oil of Scutellaria barbata. Phytochemistry, 65(7), 881-884. https:// doi.org/10.1016/j.phytochem.2004.02.005

Oluwatoyin Orhuamen, E., Kehinde Stephen, O. and Christiana Oreoluwa, A. (2012). Proximate Analysis of Fresh and Dry Leaves of Telfairia occidentalis (Hook. f.) and Talinum triangulare (Jacq.) Willd. Hrvatski časopis za prehrambenu tehnologiju, 
biotehnologiju i nutricionizam, 7(3-4), 188-191.

Shukla, A., Vats, S. and Shukla, R.K. (2015).

Phytochemical screening, proximate analysis and antioxidant activity of Dracaena reflexa Lam. leaves. Indian Journal of Pharmaceutical Sciences, 77(5), 640-644. https:// doi.org/10.4103/0250-474X.169035 